ARTICLE

\title{
Unique hole-accepting carbon-dots promoting selective carbon dioxide reduction nearly $100 \%$ to methanol by pure water
}

Yiou Wang ${ }^{1,10,12}$, Xu Liu ${ }^{1,12}$, Xiaoyu Han ${ }^{2,11}$, Robert Godin (1D ${ }^{3,4}{ }^{凶}$, Jialu Chen ${ }^{5}$, Wuzong Zhou (D) ${ }^{5}$, Chaoran Jiang ${ }^{1}$, Jamie F. Thompson ${ }^{3}$, K. Bayazit Mustafa ${ }^{1,6}$, Stephen A. Shevlin², James R. Durrant (10 ${ }^{3}$, Zhengxiao Guo (iD ${ }^{2,7,8,9 凶}$ \& Junwang Tang (i) ${ }^{1 凶}$

Solar-driven $\mathrm{CO}_{2}$ reduction by abundant water to alcohols can supply sustainable liquid fuels and alleviate global warming. However, the sluggish water oxidation reaction has been hardly reported to be efficient and selective in $\mathrm{CO}_{2}$ conversion due to fast charge recombination. Here, using transient absorption spectroscopy, we demonstrate that microwave-synthesised carbon-dots $\left({ }^{m} C D\right)$ possess unique hole-accepting nature, prolonging the electron lifetime $\left(t_{50 \%}\right)$ of carbon nitride $(\mathrm{CN})$ by six folds, favouring a six-electron product. ${ }^{\mathrm{m}} \mathrm{CD}$-decorated $\mathrm{CN}$ stably produces stoichiometric oxygen and methanol from water and $\mathrm{CO}_{2}$ with nearly $100 \%$ selectivity to methanol and internal quantum efficiency of $2.1 \%$ in the visible region, further confirmed by isotopic labelling. Such ${ }^{\mathrm{m}} \mathrm{CD}$ rapidly extracts holes from $\mathrm{CN}$ and prevents the surface adsorption of methanol, favourably oxidising water over methanol and enhancing the selective $\mathrm{CO}_{2}$ reduction to alcohols. This work provides a unique strategy for efficient and highly selective $\mathrm{CO}_{2}$ reduction by water to high-value chemicals.

\footnotetext{
${ }^{1}$ Department of Chemical Engineering, University College London, Torrington Place, London WC1E 7JE, UK. ${ }^{2}$ Department of Chemistry, University College London, 20 Gordon Street, London WC1H OAJ, UK. ${ }^{3}$ Department of Chemistry, Imperial College London, Exhibition Road, London SW7 2AZ, UK.

${ }^{4}$ Department of Chemistry, The University of British Columbia, Kelowna, BC V1V 1V7, Canada. ${ }^{5}$ School of Chemistry, University of St. Andrews, St. Andrews KY16 9ST, UK. ${ }^{6}$ Nanotechnology Research and Application Center, Sabancı University, Orta Mahallesi, Üniversite Cd. No: 27,34956 Tuzla/İstanbul, Turkey. ${ }^{7}$ Department of Chemistry, HKU-CAS Joint Laboratory on New Materials, The University of Hong Kong, Hong Kong, China. ${ }^{8}$ Department of Mechanical Engineering, The University of Hong Kong, Hong Kong, China. ${ }^{9} \mathrm{HKU}$ Zhejiang Institute of Research and Innovation, The University of Hong Kong, Hangzhou, China. ${ }^{10}$ Present address: Chair for Photonics and Optoelectronics, Nano-Institute Munich, Ludwig-Maximilians-Universität München, Königinstr. 10, 80539 Munich, Germany. ${ }^{11}$ Present address: Department of Chemistry, The University of Manchester, Oxford Road, Manchester M13 9PL, UK. ${ }^{12}$ These

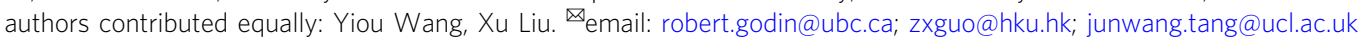


T he consumption of fossil fuels has been increasing the level of atmospheric $\mathrm{CO}_{2}$ and consequently causing imminent climate change ${ }^{1-3}$. To mitigate energy and environmental issues as well as generate sustainable fuels, people have devoted continuous efforts to reproducing natural photosynthesis to fix $\mathrm{CO}_{2}$ to sugar since the $1970 \mathrm{~s}^{4,5}$. In an ideal photocatalytic $\mathrm{CO}_{2}$ conversion system, a semiconductor is excited by photons of appropriate energy and generates pairs of electrons and holes. These then transfer to the surface to reduce $\mathrm{CO}_{2}$ and oxidise water, competing with the undesired electron-hole recombination. Such recombination occurs at $<\mu$ s timescale, much faster than the water oxidation by holes, which proceeds at $\sim 1 \mathrm{~s}$ timescale ${ }^{6}$. Therefore, it remains challenging to reduce $\mathrm{CO}_{2}$ by pure water and benchmark systems mostly use sacrificial hole acceptors, instead of water, to rapidly scavenge holes and prolong the lifetime of photoelectrons ${ }^{7,8}$. Although the efficiencies of $\mathrm{CO}_{2}$ reduction have been increased by a few orders of magnitude in recent years, the majority of these systems are uneconomical and unsustainable ${ }^{7,8}$. In order to replace those sacrificial regents by abundant water to achieve sustainable $\mathrm{CO}_{2}$ conversion, one has to develop satisfactory semiconductors with long-lived charge carriers as well as co-catalysts to extract the photoholes, thus favouring the water oxidation reaction instead of charge recombination.

Carbon nitrides, which always comprise carbon, nitrogen and hydrogen instead of ideal structure $\mathrm{C}_{3} \mathrm{~N}_{4}$ when prepared in the laboratory ${ }^{9}$ (denoted $\mathrm{CN}$ herein), is an emerging group of easyto-tune organic semiconductors ${ }^{10-12}$ and has demonstrated uncommonly-observed long-lived charge carriers owing to its unique defective structure ${ }^{13,14}$. In the presence of reduction cocatalysts and visible-light illumination, $\mathrm{CN}$ has shown promising activities in hydrogen production and $\mathrm{CO}_{2}$ reduction due to its negatively-positioned conduction band $(\mathrm{CB})^{15-19}$. However, there are only a few reports on water oxidation using $\mathrm{CN}$, because its valence band $(\mathrm{VB})$ is too close to the water oxidation potential as well as the inherent kinetic challenge of water oxidation ${ }^{17,20}$. Hence, an active co-catalyst for water oxidation is crucial to take advantage of long-lived charge carriers in $\mathrm{CN}$. Carbon-dots $(\mathrm{CD},<10 \mathrm{~nm}$ in diameter), another emerging class of carbon nanomaterials with unique electronic structures, have recently been used as co-catalysts to enhance light absorption, decompose peroxide and more importantly store electrons for reduction reactions ${ }^{17,21-24}$. Although an electron-accepting $\mathrm{CD}$ co-catalyst prolongs the lifetime of electrons, it is associated with a loss of electrochemical potential of photogenerated electrons without accelerating the sluggish water oxidation. A better solution is to apply a hole-accepting $\mathrm{CD}$ to tackle the difficult water oxidation since electron-accepting co-catalysts with a less negative $\mathrm{CB}$ waste a portion of the reductive potential of electrons photogenerated in $\mathrm{CN}$ and do not thermodynamically favour proton reduction. However, limited evidence has been reported on $\mathrm{CD}$ for its function of selective charge carriers acceptance. On the other hand, such hole-accepting CD co-catalyst, albeit decisive for improved water oxidation, has been rarely observed in experiments until now ${ }^{25-30}$.

Methanol, a useful liquid hydrogen source with the convenience of storage and transport for fuel cells ${ }^{31}$, is a more desirable reduction product from $\mathrm{CO}_{2}$ compared to $\mathrm{CO}$, methane and formic acid. However, the generation of methanol is a 6electron process, hence requiring an exceptionally prolonged lifetime of charge carriers to allow for electrons accumulation. Moreover, methanol traps holes in $\sim 10 \mathrm{~ns}$ on $\mathrm{TiO}_{2}$, and its oxidation is thus kinetically much favoured over water oxidation $(\sim 1 \mathrm{~s})^{6}$, making the continuous production of methanol a significant challenge. So far, stoichiometric production of methanol and oxygen from $\mathrm{CO}_{2}$ and water has hardly been reported with high selectivity (confirmed by isotopic labelling), long-term stability and satisfactory internal quantum yield (IQY) which is more reliable than product evolution rates (Supplementary Table 1$)^{32}$, again due to the lack of suitable co-catalysts to selectively transfer holes towards water instead of methanol. Accordingly, in order to utilise water as a sustainable hole scavenger and selectively produce methanol from $\mathrm{CO}_{2}$, we need to design an ideal hole-accepting $\mathrm{CD}$, which is mainly dependent upon our fundamental knowledge of photophysical processes ${ }^{13}$. Although transient absorption spectroscopy (TAS) plays an essential role in understanding the charge carrier dynamics of semiconductors for water splitting ${ }^{13}$, the spectroscopic characteristics in $\mathrm{CO}_{2}$ conversion processes are still unknown at ultrafast timescale, potentially hindering the rational development of target photocatalysts ${ }^{33}$.

Herein, using TAS investigation, we distinguish a unique species of $\mathrm{CD}$ as a hole acceptor in the $\mathrm{m} \mathrm{CD} / \mathrm{CN}$ composite when fabricated by a scalable microwave method $\left({ }^{\mathrm{m}} \mathrm{CD}\right.$, graphite phase). CDs could also behave as an electron acceptor in the ${ }^{\mathrm{s}} \mathrm{CD} /$ $\mathrm{CN}$ composite where they are fabricated by a sonication-based method ( ${ }^{\mathrm{s}} \mathrm{CD}$, amorphous). ${ }^{\mathrm{m}} \mathrm{CD}$ prolongs the lifetime of electrons in $\mathrm{CN}$ by a factor of four compared to ${ }^{\mathrm{s}} \mathrm{CD}$, favouring the multi-electron reduction process. Remarkably, the ${ }^{m} \mathrm{CD} / \mathrm{CN}$ nanocomposite stably produces stoichiometric oxygen and methanol with near-unity selectivity, confirmed by ${ }^{13} \mathrm{C}$ labelling, with an IQY of $2.1 \%$ at $420 \mathrm{~nm}$. On the other hand, the ${ }^{s} \mathrm{CD} / \mathrm{CN}$ composite only generates $\mathrm{CO}$, a two-electron product. Furthermore, the unique ${ }^{\mathrm{m}} \mathrm{CD}$ captures holes from electrons and prevents the adsorption of the reduction product methanol, hence favourably oxidising water instead of methanol and enhancing the selectivity of $\mathrm{CO}_{2}$ reduction to alcohols.

\section{Results}

Synthesis and characterisation of all photocatalysts. As discussed above, the widely reported electron-accepting co-catalysts with a less negative $\mathrm{CB}$ waste a portion of the reductive potential of electrons photogenerated in $\mathrm{CN}$ and do not promote the sluggish reaction between holes and water molecules. Holeaccepting co-catalysts can prolong the lifetime of photogenerated charges, preserve the reduction potential of photoelectrons on the $\mathrm{CB}$ and also turn water molecules to preferable products, e.g., $\mathrm{O}_{2}$, thus meeting our targeted ideal system for $\mathrm{CO}_{2}$ conversion. Therefore, an efficient hole-accepting co-catalyst is highly sought after for photon-driven $\mathrm{CO}_{2}$ reduction. We explored $\mathrm{CD}$ cocatalysts by synthesising two $\mathrm{CD}$ samples according to different recipes, and their properties were then investigated via extensive and thorough characterisations. Both carbon-dots were loaded to $\mathrm{CN}$ at their optimal concentrations: $3.5 \%$ for ${ }^{\mathrm{m}} \mathrm{CD} / \mathrm{CN}$ and $3 \%$ for ${ }^{\mathrm{s}} \mathrm{CD} / \mathrm{CN}$, respectively.

The novel ${ }^{\mathrm{m}} \mathrm{CD}$ were synthesised via a modified 10-minute microwave method from urea and citric acid precursors, much faster than other reported methods for high-quality $C D^{17,24,28}$. Then the purified ${ }^{\mathrm{m}} \mathrm{CD}$ were dissolved with dicyandiamide (DCDA, a precursor for $\mathrm{CN}$ ) in DMF and stirred for ten hours at $60^{\circ} \mathrm{C}$ before transferring into a ceramic crucible, followed by thermal polymerisation at $500{ }^{\circ} \mathrm{C}$ and exfoliation processes to obtain ${ }^{\mathrm{m}} \mathrm{CD} /$ $\mathrm{CN}$. For comparison, the other carbon-dots reported as reduction co-catalysts were fabricated via an alkali-assisted sonication treatment of glucose precursor $\left({ }^{\mathrm{s}} \mathrm{CD}\right)$ and loaded to carbon nitride to form ${ }^{\mathrm{s}} \mathrm{CD} / \mathrm{CN}^{30}$. Pristine $\mathrm{CN}$ was synthesised from a DCDA precursor followed by identical thermal oxidation etching ${ }^{34}$. Detailed nanocomposite photocatalyst preparation procedures and other characterisation methods are listed in the Method.

Powder X-ray diffraction (PXRD) patterns were measured (Fig. 1a) to obtain the crystallinity information of $\mathrm{CN},{ }^{\mathrm{m}} \mathrm{CD} / \mathrm{CN}$ 


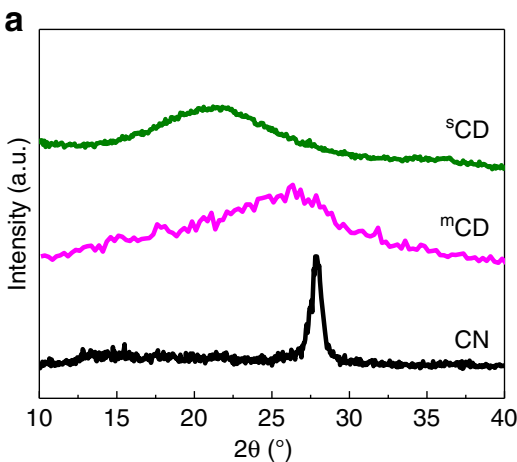

b

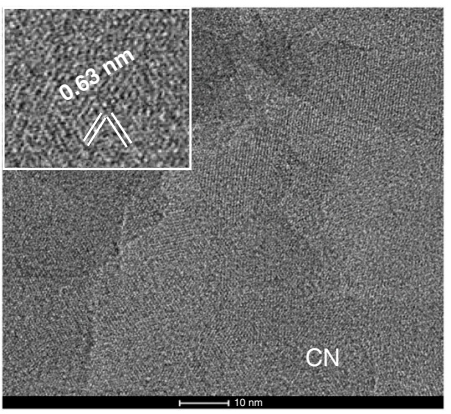

e

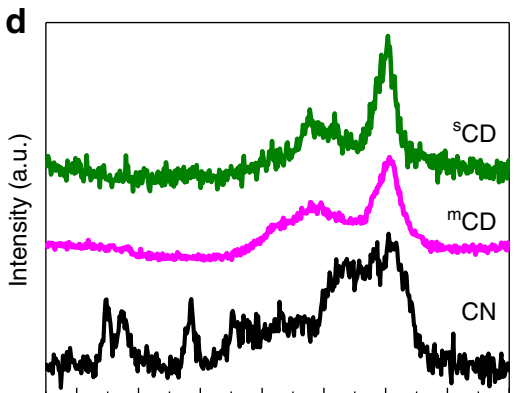

600800100012001400160018002000 Wavenumber $\left(\mathrm{cm}^{-1}\right)$



c

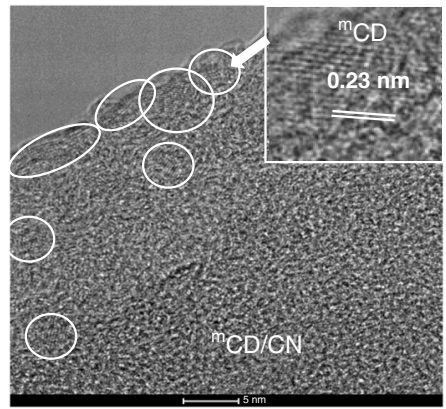

f

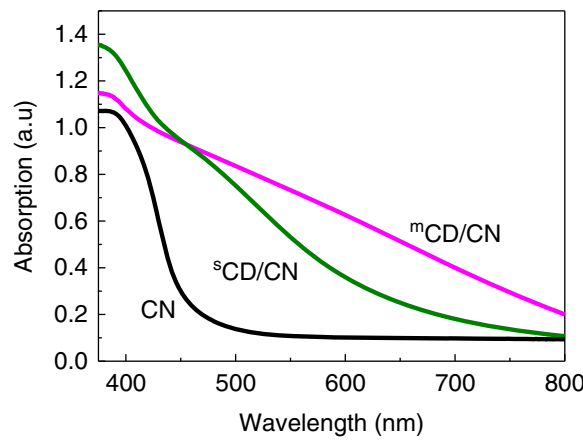

Fig. 1 Characterisation of $\mathbf{C N}, \mathbf{m} \mathbf{C D} / \mathbf{C N}$ and $\mathbf{s} \mathbf{C D} / \mathbf{C N}$. a PXRD pattern of ${ }^{\mathrm{m} C D},{ }^{\mathrm{s}} \mathrm{CD}$ and $\mathrm{CN}$. b HRTEM images of CN. Scale bar: 10 nm. Inset: an enlarged

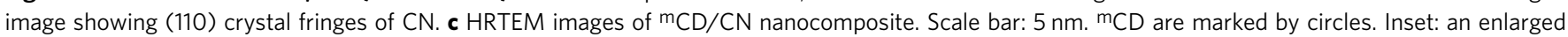
image showing graphite superstructure of ${ }^{\mathrm{m}} \mathrm{CD}$. d Raman, e Fourier transform infrared (FTIR) and $\mathbf{f} U \mathrm{UV}-\mathrm{vis} \mathrm{spectra}$ of ${ }^{\mathrm{m}} \mathrm{CD},{ }^{\mathrm{s}} \mathrm{CD}$ and $\mathrm{CN}$. Source data are provided as a Source Data file.

and ${ }^{\mathrm{s}} \mathrm{CD} / \mathrm{CN}$. At first glance, both carbon-dots exhibit poor crystalline patterns. However, ${ }^{\mathrm{m}} \mathrm{CD}$ shows a broadened (002) peak around $26.5^{\circ}(3.36 \AA)$, close to the graphite structure reported in the literature 35,36 . The weak and widened band of ${ }^{\mathrm{s}} \mathrm{CD}$ is positioned around $21.5^{\circ}$, far from a graphite-like pattern and may be assigned to an amorphous carbon compared to the former ${ }^{34}$. The synthesised $\mathrm{CN}$ polymer exhibits the typical diffraction signals of (002) and (100) planes at $27.4^{\circ}(3.26 \AA)$ and $13.0^{\circ}(6.82 \AA)$, respectively, indicating the successful formation of a heptazine-based polymer ${ }^{37}$. The co-existence and details of the structures of both ${ }^{\mathrm{m}} \mathrm{CD}$ and $\mathrm{CN}$ were examined by transmission electron microscopy (TEM). The as-prepared CN is graphene-like nanosheets (Fig. 1b) of several micrometres in diameter, with a very rough and crinkly surface due to the exfoliation of bulk CN (Supplementary Fig. 1a) ${ }^{34}$. High-resolution TEM (HRTEM) images of $\mathrm{CN}$ (Fig. 1b) show hexagonal lattice fringes with a characteristic d-spacing of $0.63 \mathrm{~nm}$, which matches well with the (110) planes of $\mathrm{CN}(a=1.277, c=0.649 \mathrm{~nm})^{34}$. The diameter of the ${ }^{\mathrm{C}} \mathrm{CD}$ is $2-10 \mathrm{~nm}$ (Supplementary Fig. $1 \mathrm{~b}$ ). The $\mathrm{CN}$ matrix is coherently decorated by ${ }^{\mathrm{m}} \mathrm{CDs}$, suggesting a strong interaction between the two phases (Fig. 1c and Supplementary Fig. 1d). The crystal structure of $\mathrm{CN}$ was relatively more sensitive to the electron beam irradiation and was therefore damaged after some irradiation, while that of $\mathrm{m}_{\mathrm{CD}}$ remained intact. The ${ }^{\mathrm{m}} \mathrm{CD}$ synthesised here has a graphitic structure with characteristic dspacing of about $0.23 \mathrm{~nm}$ (inset of Fig. 1c), which can be indexed to the (110) planes of a $2 \times 2 \times 1$ hexagonal super unit cell of graphite $(a=0.46$ and $c=0.67 \mathrm{~nm})$. Notably, the high magnification images reveal that ${ }^{\mathrm{m}} \mathrm{CD}$ concentrate around the $\mathrm{CN}$ edges and boundaries, which potentially enhances change transfer process to water during photocatalysis. The ${ }^{\mathrm{s}} \mathrm{CD}$ synthesised from sonication of glucose under alkaline conditions are determined to be $15-20 \mathrm{~nm}$ in diameter, bigger compared to
${ }^{m} \mathrm{CD}$ (Supplementary Fig. 1c). No long-range pattern of atomic positions was found, indicating an amorphous structure in line with the PXRD results. After the formation of a junction with $\mathrm{CN}$, the crystalline structure of ${ }^{\mathrm{S}} \mathrm{CD}$ was again hardly found in TEM, likely due to its amorphous allotropic feature. Therefore, both XRD and TEM confirm the composite samples were successfully obtained, and the dominant structural difference between both carbon-dots is that ${ }^{\mathrm{m}} \mathrm{CD}$ shows a relatively more crystallised graphite structure while ${ }^{\mathrm{s}} \mathrm{CD}$ are not well crystallised, which might result in their different functions.

Raman spectroscopy was used to examine the backbone of the materials further. Both carbon-dots show relatively weak D-band around $1350 \mathrm{~cm}^{-1}$ and G-band around $1600 \mathrm{~cm}^{-1}$. ${ }^{\mathrm{m}} \mathrm{CD}$ have a smaller $I_{\mathrm{D}} / I_{\mathrm{G}}$ height ratio (0.399) compared to ${ }^{\mathrm{s}} \mathrm{CD}(0.495)$, indicative that ${ }^{\mathrm{s}} \mathrm{CD}$ exhibits a more significant deviation from a graphitic structure ${ }^{38-40}$, in agreement with the XRD and TEM results. Characteristic vibrations of the heptazine-based structure were found on $\mathrm{CN}$, with the typical peaks in the regions of 1200-1700, 980 and $690 \mathrm{~cm}^{-1}$ (Fig. 1d) corresponding to disordered graphitic carbon-nitrogen vibrations, the symmetric $\mathrm{N}$-breathing mode of heptazine and the in-plane bending, respectively ${ }^{41,42}$. Therefore, ${ }^{\mathrm{s}} \mathrm{CD}$ shows a more defective manner, likely amorphous carbon, while ${ }^{\mathrm{m}} \mathrm{CD}$ shows a more crystalised doped-graphite feature.

Complementary FTIR spectroscopy was carried out to identify the surface functional groups on the carbon structures. The vibrations in ${ }^{\mathrm{S}} \mathrm{CD}$ are mostly $\mathrm{C}-\mathrm{C}$ vibrations at 1200 and $1450 \mathrm{~cm}^{-1}$ and show tiny $\mathrm{C}=\mathrm{O}$ signals (Fig. 1e). In the absence of a significant amount of heteroatom dopants, ${ }^{\mathrm{s}} \mathrm{CD}$ still contains many defects according to the D-band in the Raman spectrum, confirming its amorphous carbon morphology. In addition to $\mathrm{C}-\mathrm{C}$ features, ${ }^{\mathrm{m}} \mathrm{CD}$ also displayed stretching modes around 1250 and $1550 \mathrm{~cm}^{-1}$, attributable to $\mathrm{C}-\mathrm{N}$ vibrations, and $\mathrm{C}=\mathrm{O}$ 
stretching around $1730 \mathrm{~cm}^{-1}$, suggesting the existence of $\mathrm{N}$ and O moieties in graphite structure (Fig. 1e) ${ }^{40,43}$, consistent with the use of urea and citric acid precursors. The peaks around $2250-2550 \mathrm{~cm}^{-1}$ are attributed to adsorbed $\mathrm{CO}_{2}$ from the air. $\mathrm{CN}$ demonstrates a typical spectrum of carbon nitride ${ }^{15}$, exhibiting stretching and bending modes of nitrogen-containing heterocycles from $1000-1750 \mathrm{~cm}^{-1}$, and the broad feature at $3250 \mathrm{~cm}^{-1}$ is assigned to stretching modes of $-\mathrm{NH}-$ groups. Xray photoelectron spectra (XPS, Supplementary Fig. 2) again confirmed the co-existence of $\mathrm{N}\left(\mathrm{NH}_{x}, \mathrm{C}-\mathrm{N}-\mathrm{C}\right)$ and $\mathrm{O}$ species $(\mathrm{C}=\mathrm{O}, \mathrm{C}-\mathrm{O})$ in ${ }^{\mathrm{m}} \mathrm{CD}$ and ${ }^{\mathrm{m}} \mathrm{CD} / \mathrm{CN}$. After loading of both carbon-dots, the colours of samples changed obviously from pale yellow $(\mathrm{CN})$ to dark brown $\left({ }^{\mathrm{m}} \mathrm{CD} / \mathrm{CN}\right)$ or orange $\left({ }^{\mathrm{s}} \mathrm{CD} / \mathrm{CN}\right)$. UVvisible spectra confirmed that both carbon-dots have a generally stronger absorption than $\mathrm{CN}$ in the visible region to $600-700 \mathrm{~nm}$ (Fig. 1f), commonly observed on carbon nanomaterials ${ }^{38}$. Taking into account the graphite backbone confirmed by XRD, TEM, Raman and FTIR, we can conclude that ${ }^{\mathrm{m}} \mathrm{CD}$ is $\mathrm{N}, \mathrm{O}$-doped graphite dots, which is more crystalline compared to the amorphous ${ }^{\mathrm{S}} \mathrm{CD}$, hence shows somewhat increased visible-light absorption.

Charge carrier dynamics of all samples. As discussed above, two major obstacles hindering sustainable light-driven $\mathrm{CO}_{2}$ reduction by water are (i) the intrinsic weak reduction potential of water and (ii) the lack of fundamental understandings of charge carrier dynamics of co-catalysts. Most of the reported CDs promote reduction process as an electron acceptor while very few are distinguished as an advantageous hole acceptor for efficient water oxidation. Therefore, to understand the role of different carbondots, we investigated the charge transfer kinetics of $\mathrm{CN}, \mathrm{m}_{\mathrm{CD}} / \mathrm{CN}$ and ${ }^{\mathrm{S}} \mathrm{CD} / \mathrm{CN}$ samples after synthesis and characterisation. TAS, a powerful technique to elucidate the charge carrier dynamics of photocatalysts, was used to experimentally determine the electron-hole dynamics of ${ }^{\mathrm{m}} \mathrm{CD} / \mathrm{CN}$ and ${ }^{\mathrm{s}} \mathrm{CD} / \mathrm{CN}$ nanocomposite at $\mu$ s-s timescales. Photoexcitation of $\mathrm{CN}$ alone yields a broad absorption spanning from 450 to $1000 \mathrm{~nm}$, which peaks near 700 $\mathrm{nm}$ (Fig. 2a, dashed line). In order to determine the nature of the excited states, we first measured the TAS spectra of CN with and without $\mathrm{Ag}^{+}$ions, a well-known efficient electron scavenger which can yield long-lived holes. Kinetic traces probed at 510 and $700 \mathrm{~nm}$ (Supplementary Fig. 3a, b) show that in the presence of $\mathrm{Ag}^{+}$electron scavenger the amplitude at $700 \mathrm{~nm}$ decreases but the $510 \mathrm{~nm}$ signal enhances and features a longer-lived species. Therefore, the signal observed at $510 \mathrm{~nm}$ is mainly assigned to photogenerated holes in $\mathrm{CN}$ and the broad photoinduced signal observed at $700 \mathrm{~nm}$ is assigned to photogenerated electrons in $\mathrm{CN}$, similar to previous observations on $\mathrm{CN}^{13}$.

Turning to the CD/CN nanocomposites, the TAS spectra of ${ }^{\mathrm{m}} \mathrm{CD} / \mathrm{CN}$ (Fig. 2b) resemble that of the $\mathrm{CN}$ rather than the isolated ${ }^{\mathrm{m}} \mathrm{CD}$ (Supplementary Fig. 3c). Moreover, the change in collected probe light is on the order of $1 \%$ for both the ${ }^{\mathrm{m}} \mathrm{CD} / \mathrm{CN}$ and $\mathrm{CN}$, while it is on the order of $0.005 \%$ for ${ }^{\mathrm{m}} \mathrm{CD}$. These considerations indicate that TAS predominantly probes $\mathrm{CN}$, and the main feature observed for the ${ }^{\mathrm{m}} \mathrm{CD} / \mathrm{CN}$ nanocomposite remains that of electrons localised in $\mathrm{CN}$. Compared to the results with $\mathrm{CN}$, the amplitude of the $700 \mathrm{~nm}$ feature (electron signals in $\mathrm{CN}$ ) is higher (increasing from 1.25 to $1.5 \%$ ) in the case of ${ }^{\mathrm{m}} \mathrm{CD} /$ $\mathrm{CN}$ (Fig. 2b), suggesting that more efficient charge separation increases the number of long-lived electrons localised on $\mathrm{CN}$ at these timescales. The increased electron signal in $\mathrm{CN}$ indicates that holes were efficiently extracted from $\mathrm{CN}$ to ${ }^{\mathrm{m}} \mathrm{CD}$. In contrast, ${ }^{s} \mathrm{CD} / \mathrm{CN}$ shows a smaller signal amplitude than pure $\mathrm{CN}$ (decreasing from 1.25 to $0.95 \%$ at $700 \mathrm{~nm}$ ) throughout the probed window, inferring electron transfer from $\mathrm{CN}$ to ${ }^{\mathrm{s}} \mathrm{CD}$. The addition of $\mathrm{AgNO}_{3}$ does not affect the signal (Fig. 2c,f), suggesting that electrons were already effectively extracted from $\mathrm{CN}$ by ${ }^{\mathrm{s}} \mathrm{CD}$.

The half-life time (for an initial time $t_{0}=2 \mu \mathrm{s}$ ) of the signal observed at $700 \mathrm{~nm}$ increases over 6-fold from $25 \mu$ s (CN) to $160 \mu \mathrm{s}\left({ }^{\mathrm{m}} \mathrm{CD} / \mathrm{CN}\right)$ (Fig. $2 \mathrm{~g}$ ), indicating suppressed electron-hole recombination due to charge separation across the ${ }^{\mathrm{m}} \mathrm{CD} / \mathrm{CN}$ junction. A long-lived shoulder near $550 \mathrm{~nm}$ for ${ }^{\mathrm{s}} \mathrm{CD} / \mathrm{CN}$ was also noted, in line with the $510 \mathrm{~nm}$ feature of holes residing in $\mathrm{CN}$. A slight increase in $t_{50 \%}$ (from 25 to $40 \mu \mathrm{s}$ ) compared to bare CN (Fig. 2g) was attributed to the separation of charges by ${ }^{\mathrm{s}} \mathrm{CD}$. These observations are consistent with the hypothesis of the extraction of electrons from $\mathrm{CN}$ by ${ }^{\mathrm{s}} \mathrm{CD}$. The $\mu \mathrm{s}$-TAS decay at $700 \mathrm{~nm}$ is well represented by a power law of the form $I \propto t^{-\alpha}$, as evidenced by the linear decay on a log-log plot, indicating a trapping-detrapping dynamics (Fig. 2h) ${ }^{13}$. Briefly, we have identified the desired hole-accepting ${ }^{\mathrm{m}} \mathrm{CD}$ co-catalyst in the ${ }^{\mathrm{m}} \mathrm{CD} / \mathrm{CN}$ composite. Different functions of two $\mathrm{CDs}$ could be seen for charge separation, and the specific $\mathrm{CD} / \mathrm{CN}$ interaction can influence the direction of charge transfer.

Photocatalytic $\mathrm{CO}_{2}$ conversion to methanol. After identification of the different structures and physical functions of these junctions, the activity of the photocatalysts for reduction of $\mathrm{CO}_{2}$ in pure water was evaluated under 1 bar of $\mathrm{CO}_{2}$ at room temperature under visible-light irradiation $(\lambda>420 \mathrm{~nm}$; see Supplementary Figs. 6-8 for raw data and calibration curve).

The ${ }^{\mathrm{m}} \mathrm{CD} / \mathrm{CN}$ nanocomposite, which contained hole-accepting ${ }^{m} \mathrm{CD}$, exhibits a remarkably enhanced activity towards the production of methanol and oxygen from $\mathrm{CO}_{2}$ photoreduction with water as the only electron donor (Fig. 3a). The concentration of ${ }^{\mathrm{m}} \mathrm{CD}$ was optimised to $3.5 \%$ wt (Supplementary Fig. 5a), presumably, to balance light absorption and reaction sites for water oxidation since further increases in the ${ }^{\mathrm{m}} \mathrm{CD}$ concentration lowers the photoactivity. The yields of both methanol and $\mathrm{CO}$ on ${ }^{m} \mathrm{CD}$ (3.5)/CN increase nearly linearly over time (Supplementary Fig. $5 \mathrm{~b}$ ) and the average production rates are 13.9 and $0.05 \mu \mathrm{mol} /$ $\mathrm{g} / \mathrm{h}$, showing a $\sim 99.6 \pm 0.2 \%$ (calculated from three consecutive runs) selectivity towards methanol. Moreover, $\mathrm{O}_{2}$ is evolved as the only oxidation product, and the evolved amount increases linearly with the reaction time, similar to the production profile of $\mathrm{CO}$ and methanol (Supplementary Fig. 5b). The ratio of $\mathrm{O}_{2}$ to methanol is about $1.45: 1$, very close to the expected stoichiometric ratio of $1.5: 1$ when assuming all generated electrons reduce $\mathrm{CO}_{2}$ to methanol and all holes oxidise water to $\mathrm{O}_{2}$. Neither $\mathrm{H}_{2}$ nor oxidation products other than $\mathrm{O}_{2}$ were detected. The evolution of stoichiometric $\mathrm{O}_{2}$ again confirms the significance of the unique function of hole-accepting ${ }^{\mathrm{m}} \mathrm{CD}$.

On the contrary, ${ }^{\mathrm{s}} \mathrm{CD}$ as a reduction co-catalyst was also optimised to a $3 \%$ loading on $\mathrm{CN}$ to form ${ }^{\mathrm{s}} \mathrm{CD} / \mathrm{CN}$, which only produces the two-electron product $\mathrm{CO}$ instead of the six-electron product methanol, together with negligible $\mathrm{O}_{2}$ gas (Fig. 3b). This is not surprising because $\mathrm{CN}$ itself can hardly produce oxygen in the absence of hole-accepting co-catalysts and ${ }^{\mathrm{s}} \mathrm{CD}$ here is an electron acceptor as proved by our TAS results, which facilitate $\mathrm{CO}_{2}$ reduction to $\mathrm{CO}$. A similar $\mathrm{CD} / \mathrm{g}-\mathrm{C}_{3} \mathrm{~N}_{4}$ junction was previously reported for $\mathrm{CO}_{2}$ reduction to $\mathrm{CO}$ and others ${ }^{30}$. A tiny amount of generated $\mathrm{O}_{2}$ might also be dissolved in water, consumed via back reactions or below the detection limit of GC. In total, the photocatalytic activity of ${ }^{\mathrm{m}} \mathrm{CD} / \mathrm{CN}$ is ca. 12 times higher than ${ }^{\mathrm{s}} \mathrm{CD} / \mathrm{CN}$ for $\mathrm{CO}_{2}$ reduction under identical experimental conditions.

Several control experiments were also performed (Fig. 3c): (i) without a $\mathrm{CO}_{2}$ feed (for ${ }^{\mathrm{m}} \mathrm{CD} / \mathrm{CN}$ nanocomposite), (ii) in the absence of a photocatalyst and (iii) with a lack of light. Under 

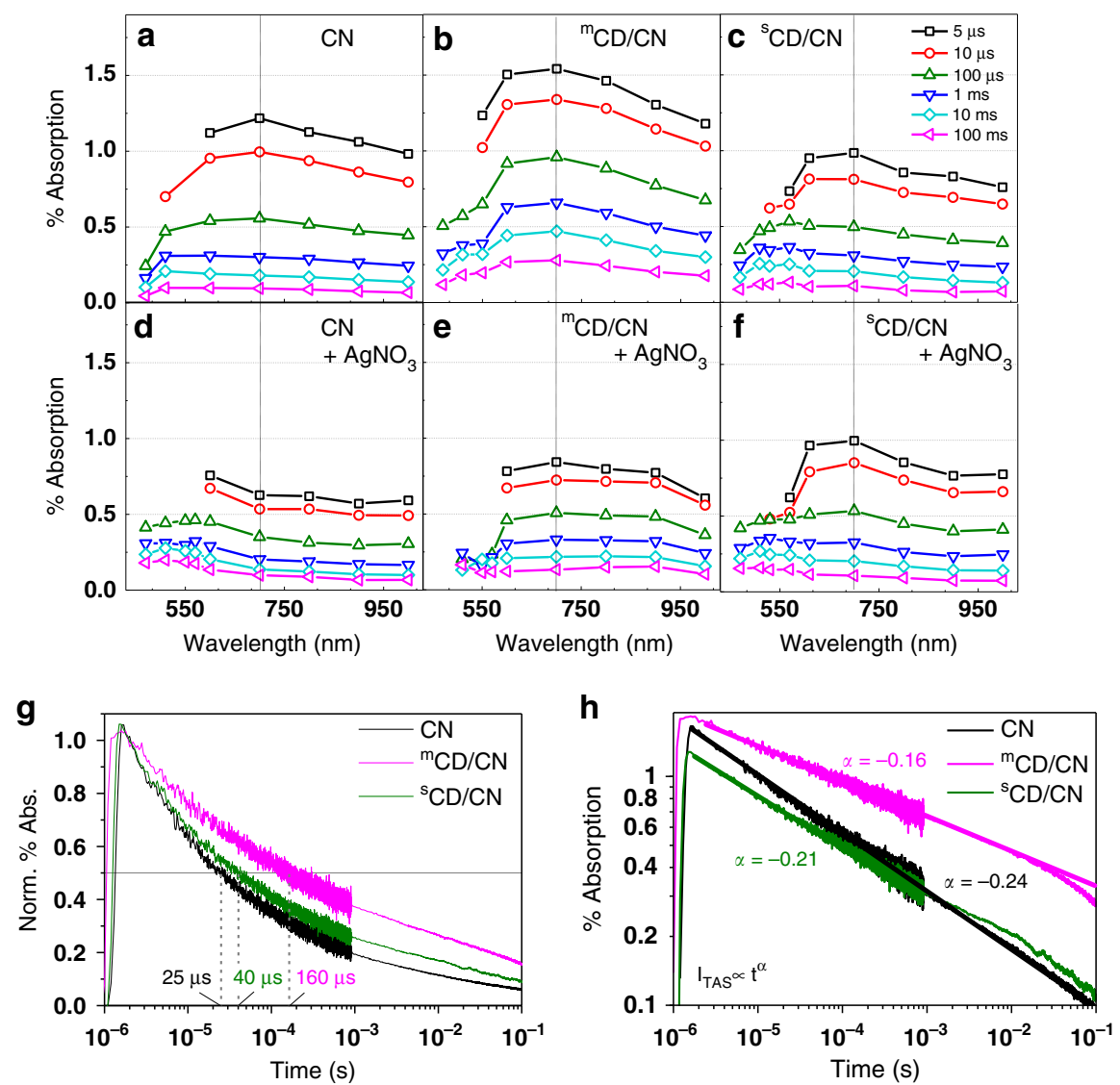

Fig. 2 TAS measurements of $\mathbf{C N},{ }^{\mathbf{m}} \mathbf{C D} / \mathbf{C N}$ and ${ }^{\mathbf{s}} \mathbf{C D} / \mathbf{C N}$. Diffuse reflectance $\mathrm{TAS}$ spectra for samples with (a-c) and without (d-f) $10 \mathrm{mM} A g N \mathrm{O}_{3}$. $\mathrm{CN}$ $(\mathbf{a}, \mathbf{d}),{ }^{\mathrm{m}} \mathrm{CD} / \mathrm{CN}(\mathbf{b}, \mathbf{e})$ and ${ }^{\mathrm{S}} \mathrm{CD} / \mathrm{CN}(\mathbf{c}, \mathbf{f})$ were dispersed in aqueous solution. The change of signal amplitude at $700 \mathrm{~nm}$ indicates it should be mainly assigned to the electron signal in $\mathrm{CN}$ and ${ }^{\mathrm{m}} \mathrm{CD}$ improves the charge separation on $\mathrm{CN}$ due to hole transfer from $\mathrm{CN}$ to $\mathrm{m} C D$. $\mathbf{g} \mu \mathrm{s}-\mathrm{TAS}$ decay kinetics of $\mathrm{CN}$, ${ }^{\mathrm{m}} \mathrm{CD} / \mathrm{CN}$ and ${ }^{\mathrm{S}} \mathrm{CD} / \mathrm{CN}$ in water monitored at $700 \mathrm{~nm}$ and excited by pulsed $355 \mathrm{~nm}$ excitation $\left(460 \mu \mathrm{J} / \mathrm{cm}^{2}\right)$ and $\mathbf{h}$ fitted $\alpha$ parameters indicated in the same color as the associated trace. Source data are provided as a Source Data file.

these conditions, the production of both $\mathrm{CO}$ and methanol were negligible, indicating that the $\mathrm{CN}$ and ${ }^{\mathrm{m}} \mathrm{CD}$ could not be decomposed to the products under irradiation. Also, ${ }^{\mathrm{m}} \mathrm{CD}$ or pure $\mathrm{CN}$ showed nearly zero activity. The physical mixture of ${ }^{\mathrm{m}} \mathrm{CD}$ and $\mathrm{CN}$ was also tested and showed no evident activity compared to pure $\mathrm{CN}$, which also supports that a strong interaction between ${ }^{\mathrm{m}} \mathrm{CD} / \mathrm{CN}$ was only prepared in situ by microwave heating and is crucial for $\mathrm{CO}_{2}$ photoreduction.

Isotopic measurement is crucial to avoid misleading information because inevitable organic impurities in carbon-based catalysts can possibly be oxidised to hydrocarbons (e.g., methanol or other organic products). To further confirm the conversion of $\mathrm{CO}_{2}$, the photoreduction of ${ }^{13} \mathrm{C}$-labeled $\mathrm{CO}_{2}$ was conducted over the ${ }^{\mathrm{m}} \mathrm{CD} / \mathrm{CN}$ photocatalyst. Dominant peaks of ${ }^{13} \mathrm{CO}(\mathrm{m} / z=29)$ and ${ }^{13} \mathrm{CH}_{3} \mathrm{OH}^{+}(m / z=33)$ were observed at $m / z=29,32$ and 33 , which were assigned to ${ }^{13} \mathrm{CO},{ }^{13} \mathrm{CH}_{3} \mathrm{OH}^{+}$and fragments of ${ }^{13} \mathrm{CH}_{3} \mathrm{O}^{+}$produced during the MS measurement (Fig. $3 \mathrm{~d}$ ). The evidence indicates that the evolved products originate from the photoreduction of ${ }^{13} \mathrm{CO}_{2}$.

Three consecutive runs were then carried out over the ${ }^{\mathrm{m}} \mathrm{CD} /$ $\mathrm{CN}$ photocatalyst (Fig. 3e) to investigate its stability. The $\mathrm{CO}$ and methanol evolution rates did not show noticeable changes, indicating the excellent stability of the nanocomposite. For comparison with other reported systems, quantum yield (QY) is the more preferable and more reliable metric to evaluate one material's property rather than activity, since the total production rate is highly dependent on the experimental conditions 9 . The IQY (Fig. 3f) of the optimised ${ }^{\mathrm{m}} \mathrm{CD} / \mathrm{CN}$ photocatalyst was measured to be $2.1 \%$ at $\lambda=420 \mathrm{~nm}, 0.7 \%$ at $\lambda=500 \mathrm{~nm}$ and $0.4 \%$ at even $\lambda=600 \mathrm{~nm}$ under 1 bar conditions at room temperature, which is over an order of magnitude higher than that recently reported for $\mathrm{CN}(0.076 \% \text { at } 420 \mathrm{~nm})^{30}$. The IQYs at longer wavelengths might be due to the light absorption of ${ }^{\mathrm{m}} \mathrm{CD}$ or ${ }^{\mathrm{m}} \mathrm{CD} / \mathrm{CN}$ interfacial states as $\mathrm{CN}$ could not harvest $500-600 \mathrm{~nm}$ photons by itself. Long-lived TAS signal attributed to charges is observed in the ${ }^{\mathrm{m}} \mathrm{CD} / \mathrm{CN}$ composite but not with $\mathrm{CN}$ alone under $600 \mathrm{~nm}$ excitation (Supplementary Fig. 4). Therefore, water has been successfully used as the sole electron source in the photoreduction of $\mathrm{CO}_{2}$, and for the first time, methanol was produced with nearly unity selectivity in one step under visiblelight.

To further demonstrate the improved properties of the ${ }^{\mathrm{m}} \mathrm{CD} /$ $\mathrm{CN}$ composite, we prepared and tested photoelectrodes. The photocurrent of $\mathrm{m} \mathrm{CD} / \mathrm{CN}$ photoanode is approximately twice higher than that of the $\mathrm{CN}$ photoanode (Supplementary Fig. $5 \mathrm{c}$ ), demonstrating the improved separation efficiency of photoexcited charge carriers in ${ }^{\mathrm{m}} \mathrm{CD} / \mathrm{CN}$ and nature of hole acceptor of ${ }^{\mathrm{m}} \mathrm{CD}$, which agrees with the results of $\mathrm{CO}_{2}$ photoconversion. To better understand the photophysical characteristics of photoinduced charge carriers in photocatalysts, the ns-level time-resolved


Fig. 5d). The ${ }^{\mathrm{m}} \mathrm{CD} / \mathrm{CN}$ presents slower decay kinetics compared with pure $\mathrm{CN}$, namely, the photogenerated charge carriers in


lifetimes of the carriers $\left(\tau_{\text {avg }}\right)$ were determined to be $\sim 15.3$ and $13.3 \mathrm{~ns}$ for ${ }^{\mathrm{m}} \mathrm{CD} / \mathrm{CN}$ and $\mathrm{CN}$ according to the fitting calculation, 

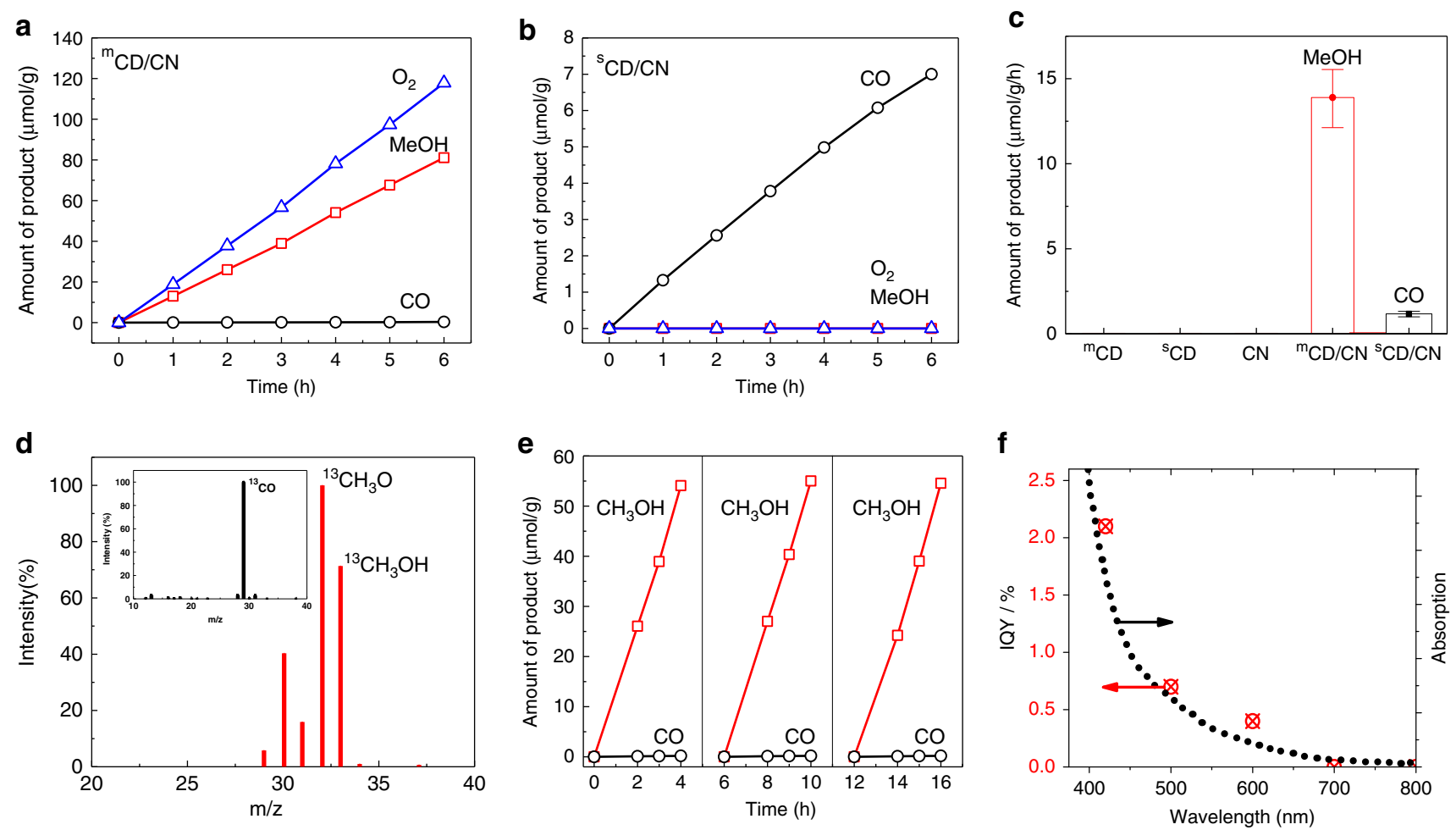

Fig. 3 Photocatalytic $\mathbf{C O}_{\mathbf{2}}$ conversion to methanol. The photocatalytic activity of a $\mathrm{m} C D / C N$ and $\mathbf{b}$ s $C D / C N$ measured under visible light $(\lambda>420$ nm). c Control experiments on ${ }^{\mathrm{m} C D},{ }^{\mathrm{s}} \mathrm{CD}, \mathrm{CN},{ }^{\mathrm{m}} \mathrm{CD} / \mathrm{CN}$ and ${ }^{\mathrm{s}} \mathrm{CD} / \mathrm{CN}$. Error bar: $\mathrm{m} C D / C N 13.9 \pm 1.7 \mu \mathrm{mol} / \mathrm{g} / \mathrm{h},{ }^{\mathrm{s}} \mathrm{CD} / \mathrm{CN} 1.2 \pm 0.2 \mu \mathrm{mol} / \mathrm{g} / \mathrm{h}$. d Mass spectra of the product ${ }^{13} \mathrm{CH}_{3} \mathrm{OH}$ from ${ }^{13} \mathrm{CO}_{2}$ photoconversion by the ${ }^{\mathrm{m}} \mathrm{CD} / \mathrm{CN}$ photocatalyst. Inset: the mass spectra of the ${ }^{13} \mathrm{CO}_{\text {from }}{ }^{13} \mathrm{CO}_{2}$ photoconversion over the ${ }^{\mathrm{m}} \mathrm{CD} / \mathrm{CN}$ photocatalyst. e Consecutive three runs of $\mathrm{CO}_{2}$ photoconversion to methanol on $\mathrm{m} C D / C N$ under visible light. $\mathbf{f} \mathrm{IQY}$ of $\mathrm{m} C D / C N$ measured at atmospheric pressure under nearly one sun irradiation condition. Source data are provided as a Source Data file.

respectively, supporting better electron transfer and higher charge separation efficiency in ${ }^{\mathrm{m}} \mathrm{CD} / \mathrm{CN}$.

It seems ideal that methanol, a highly desirable product from $\mathrm{CO}_{2}$ conversion, has been produced with near-unity selectivity and remains intact. This is particularly remarkable because methanol is among the most commonly used holes scavengers for hydrogen production from water as it is easily and rapidly oxidised ( $10 \mathrm{~ns}$ timescale), as mentioned above. How can methanol be conserved as an inert product in a photocatalytic system which generates holes continuously? To elucidate the high selectivity of the $\mathrm{m}_{\mathrm{CD}} \mathrm{CN}$ junction for $\mathrm{H}_{2} \mathrm{O}$ oxidation and methanol production, we employed theoretical calculations of adsorption energy based on Density Functional Theory (DFT). The calculations were carried out using the Vienna ab-initio Simulation Package (VASP) ${ }^{44}$. To mimic the structure of the ${ }^{m} \mathrm{CD}$, the model (Supplementary Fig. 9c) consisting of a coronene (Supplementary Fig. 9a) with a pyrene (Supplementary Fig. 9b) on the top was placed in a $20 \times 20 \times 10 \AA^{3}$ box. Two nano-flakes were symmetrically mass-centred with a relaxed interlayer distance of $3.37 \AA$, consistent with the XRD and HRTEM observation (Fig. 1a,c). This model has been proven effective to mimic the CD (Supplementary Fig. 9a-c) ${ }^{39}$. For the CN, we have adopted the structures used in the previous calculations (Supplementary Fig. 9d,e) ${ }^{22}$. Detailed computational settings are illustrated in the SI.

The adsorption energy, $E_{\mathrm{ad}}$, was calculated according to

$$
E_{\text {ad }}=E_{\text {total }}-\left(E_{\text {adsorbate }}+E_{\text {adsorbent }}\right)
$$

where $E_{\text {total }}, E_{\text {adsorbate }}$ and $E_{\text {adsorbent }}$ represent the energies of the absorbing system, the adsorbate and the adsorbent at equilibrium configurations, respectively. According to the calculated adsorption energy of the most stable configurations (Supplementary
Tables 3 and 5), both $\mathrm{CO}_{2}$ and more importantly $\mathrm{CH}_{3} \mathrm{OH}$ bind more favourably to $\mathrm{CN}$ rather than ${ }^{\mathrm{m}} \mathrm{CD}$ (Fig. 4a left and middle). On the contrary, $\mathrm{H}_{2} \mathrm{O}$ molecules prefer to be absorbed on the surface of $\mathrm{m}_{\mathrm{CD}}$ instead of $\mathrm{CN}$ (Fig. 4a right). According to the TAS results and calculations of $\mathrm{E}_{\mathrm{ad}}$ on $\mathrm{m}_{\mathrm{CD}} / \mathrm{CN}, \mathrm{CN}$ maintains electrons and adsorb $\mathrm{CO}_{2}$, while ${ }^{\mathrm{m}} \mathrm{CD}$ selectively accepts holes and absorbs $\mathrm{H}_{2} \mathrm{O}$. Hence for the ${ }^{\mathrm{m}} \mathrm{CD} / \mathrm{CN}$ composite, $\mathrm{CO}_{2}$ is reduced by photoelectrons on $\mathrm{CN}$ and photoholes on ${ }^{\mathrm{m}} \mathrm{CD}$ are preferably used to oxidise $\mathrm{H}_{2} \mathrm{O}$ instead of methanol. Based on the above results, a pathway of visible-light-driven $\mathrm{CO}_{2}$ photoconversion on ${ }^{\mathrm{m}} \mathrm{CD} / \mathrm{CN}$ has been proposed in Fig. 4b. Electron-hole pairs are generated in $\mathrm{CN}$ under visible-light excitation. Photoelectrons accumulate on the surface of $\mathrm{CN}$ where $\mathrm{CO}_{2}$ reduction to $\mathrm{CH}_{3} \mathrm{OH}$ occurs, while photoholes transfer from $\mathrm{CN}$ to the surface of ${ }^{\mathrm{m}} \mathrm{CD}$ to oxidise $\mathrm{H}_{2} \mathrm{O}$ into $\mathrm{O}_{2}$. On the other hand, for ${ }^{\mathrm{s}} \mathrm{CD} / \mathrm{CN}, \mathrm{CO}_{2}$ reduction takes place on electron-accepting ${ }^{\mathrm{s}} \mathrm{CD}$ to produce $\mathrm{CO}$ while the holes on $\mathrm{CN}$ relatively slowly oxidise $\mathrm{H}_{2} \mathrm{O}$ molecules or oxidise methanol if produced. Thus, $\mathrm{CO}$ could come from both direct reduction of $\mathrm{CO}_{2}$ and the subsequent oxidation of methanol, which is difficult to distinguish in this case.

To confirm the compatibility of methanol with ${ }^{\mathrm{m}} \mathrm{CD} / \mathrm{CN}$ to rationalise the high selectivity to methanol experimentally, we directly tested the oxidation of methanol by ${ }^{\mathrm{m}} \mathrm{CD} / \mathrm{CN}$ and $\mathrm{CN}$. Figure $4 \mathrm{c}$ shows that under visible-light, methanol can be readily oxidised to $\mathrm{CO}$ by photoholes of pure $\mathrm{CN}$, which might be the reason why there is no methanol produced by ${ }^{\mathrm{s}} \mathrm{CD} / \mathrm{CN}$. Interestingly, in the ${ }^{\mathrm{m}} \mathrm{CD} / \mathrm{CN}$ system, no $\mathrm{CO}$ was detected, consistent with the theoretical calculations that methanol could not be readily adsorbed on the surface of ${ }^{\mathrm{m}} \mathrm{CD}$ where holes accumulate, and photooxidation of water occurs. Therefore, the ${ }^{\mathrm{m}} \mathrm{CD}$ possesses the unique functions of selectively accepting 

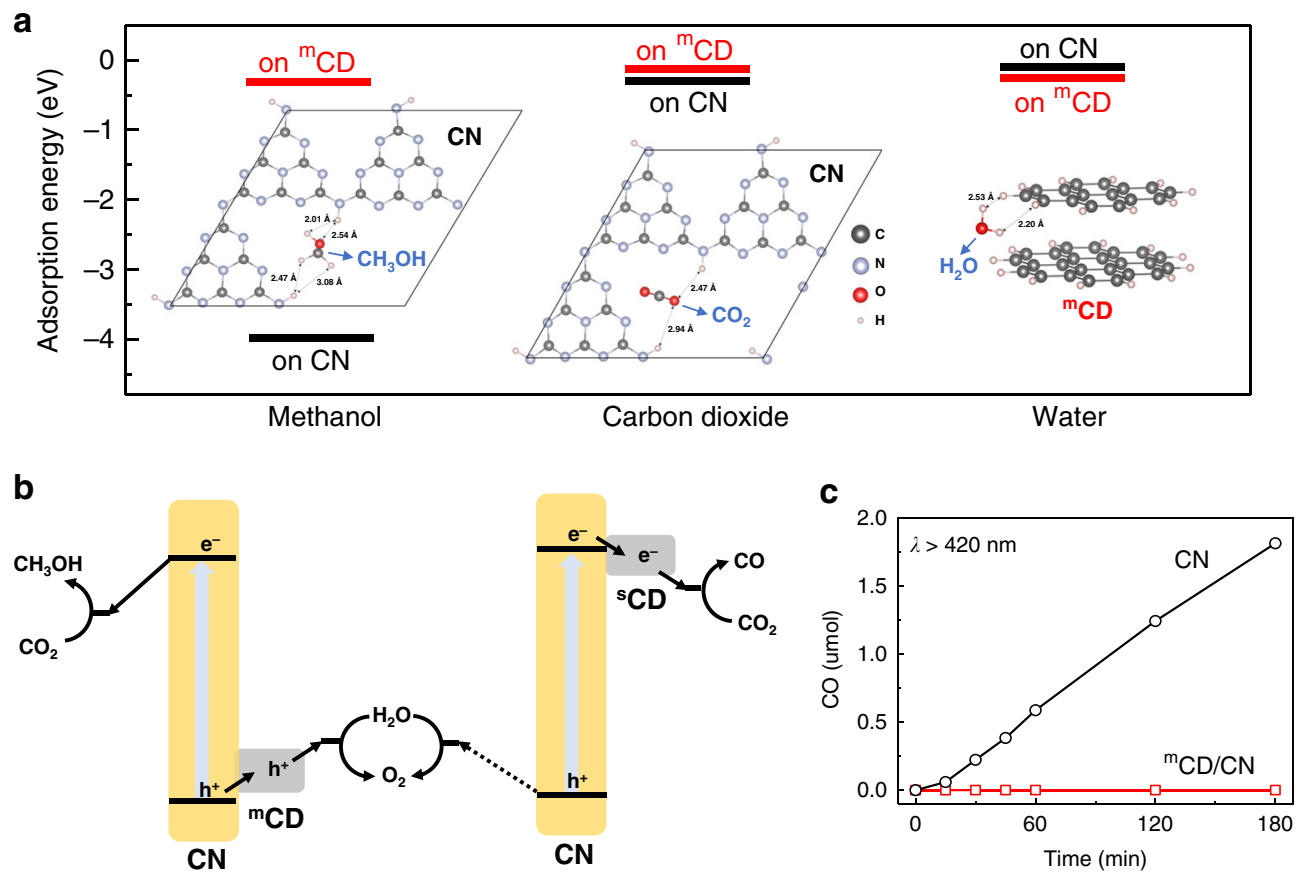

Fig. 4 The fundamental understanding of the high selectivity to methanol. a Adsorption energies and the most stable configurations of $\mathrm{CO}_{2}$ and $\mathrm{CH}_{3} \mathrm{OH}$ on $\mathrm{CN}$ and $\mathrm{H}_{2} \mathrm{O}$ on ${ }^{m} \mathrm{CD}$. b Schematic diagram of photocatalytic $\mathrm{CO}_{2}$ reduction by the ${ }^{\mathrm{m}} \mathrm{CD} / \mathrm{CN}$ and ${ }^{\mathrm{s}} \mathrm{CD} / \mathrm{CN}$. The band bending between catalysts and water/ $\mathrm{CO}_{2}$ is not drawn. $\mathbf{c}$ The $\mathrm{CH}_{3} \mathrm{OH}$ oxidation test on $\mathrm{CN}$ and ${ }^{\mathrm{m}} \mathrm{CD} / \mathrm{CN}$ under visible light. Source data are provided as a Source Data file.

photoholes as well as selectively absorbing water instead of methanol. Hence, the desired hole-accepting carbon-dots cocatalysts have been successfully developed to utilise water as the only electron donor in $\mathrm{CO}_{2}$ conversion and guarantees near unity selectivity of methanol. The origin of its superior performance has been rationalised by modelling as well as experiments.

\section{Discussion}

For ${ }^{\mathrm{s}} \mathrm{CD}$, its amorphous carbon nature indicates a mixture of $\mathrm{sp}^{2}$ and $s p^{3}$ species ${ }^{45}$. Hence the charge transfer is less efficient than pure $\mathrm{sp}^{2}$ hybrid of the graphite structure $\left({ }^{\mathrm{m}} \mathrm{CD}\right)$, which partially explains why the ${ }^{\mathrm{m}} \mathrm{CD}$ shows a larger enhancement of lifetime of charges. Holes on $\mathrm{CN}$ could not intrinsically oxidise water in the absence of co-catalysts. The activity of $\mathrm{O}_{2}$ production is thus negligible and $\mathrm{CO}_{2}$ reduction is not efficient due to fast charge recombination in ${ }^{\mathrm{s}} \mathrm{CD} / \mathrm{CN}$ and poor hole activity. On the other hand, ${ }^{m} \mathrm{CD} / \mathrm{CN}$ favours electron accumulation on the surface of $\mathrm{CN}$ due to efficient hole transfer to ${ }^{\mathrm{m}} \mathrm{CD}$, which facilitates a multi-electron reduction process to produce methanol instead of CO. Therefore, this study demonstrates the superiority of the design of hole-accepting co-catalysts ${ }^{\mathrm{m}} \mathrm{CD}$ to the widely reported electron acceptor ${ }^{\mathrm{S}} \mathrm{CD}$ in promoting the reaction of $\mathrm{CO}_{2}$ reduction to higher-value chemicals.

To summarise, through TAS investigations over six orders of magnitude in time on carbon-based nano architectures, we observe that ${ }^{\mathrm{s}} \mathrm{CD}$ work as an electron acceptor in ${ }^{\mathrm{s}} \mathrm{CD} / \mathrm{CN}$, while ${ }^{\mathrm{m}} \mathrm{CD}$ serves as a notable hole acceptor in ${ }^{\mathrm{m}} \mathrm{CD} / \mathrm{CN}$ after excitation. Charge separation across the $\mathrm{CD} / \mathrm{CN}$ interface increases the lifetime of the charge carriers from $25 \mu \mathrm{s}(\mathrm{CN})$ to $160 \mu \mathrm{s}(\mathrm{m} \mathrm{CD} /$ $\mathrm{CN})$ or only $40 \mu \mathrm{s}\left({ }^{\mathrm{s}} \mathrm{CD} / \mathrm{CN}\right)$ and enhances participation in subsequent $\mathrm{CO}_{2}$ conversion. The differences in photophysical functions of $\mathrm{CDs}$ result in the differences in both conversion efficiency and more importantly, selectivity. ${ }^{\mathrm{s}} \mathrm{CD} / \mathrm{CN}$ junction converts $\mathrm{CO}_{2}$ into $\mathrm{CO}$ while the ${ }^{\mathrm{m}} \mathrm{CD} / \mathrm{CN}$ junction could unprecedentedly and selectively reduce $\mathrm{CO}_{2}$ to methanol, which has been further confirmed by ${ }^{13} \mathrm{C}$ labelling with nearly unity selectivity. Furthermore, the ${ }^{\mathrm{m}} \mathrm{CD} / \mathrm{CN}$ composite is c.a. 12 times more active than ${ }^{\mathrm{s}} \mathrm{CD} / \mathrm{CN}$ for $\mathrm{CO}_{2}$ conversion observed under the same experimental conditions.

Such ${ }^{\mathrm{m}} \mathrm{CD}$ show more favourable water adsorption yet unfavourable methanol adsorption compared to $\mathrm{CN}$, thus facilitating selective oxidation of water to $\mathrm{O}_{2}$ while avoiding unproductive oxidation of the photoreduction product, methanol. Therefore, the uncommon ${ }^{\mathrm{m}} \mathrm{CD}$ co-catalyst is a crucial reason for such high selectivity of $\mathrm{CO}_{2}$ reduction to methanol using water as the only reductant. Overall, electrons reach the surface of $\mathrm{CN}$ and possess enough chemical potential to reduce $\mathrm{CO}_{2}$, together with protons, to produce methanol with an exceptional $99.6 \pm 0.2 \%$ selectivity and high IQY of $2.1 \%$ at $420 \mathrm{~nm}$ and benchmark IQY at 500 and $600 \mathrm{~nm}$ ( 0.7 and $0.4 \%$, respectively). The unique function of holeaccepting carbon-dots should not only excite broad interest in selective photocatalytic oxidation in organic synthesis and environmental purification but also be potentially useful for promoting charge transfer in photovoltaics, photoelectrochemical devices and light-emitting diodes. This work paves a metal-free avenue to the sustainable production of methanol, which is among the most promising hydrogen sources for fuel cells.

\section{Methods}

Materials preparations. All chemical reagents were analytical grade and were used without further purification. Citric acid, $N, N$-dimethylformamide (DMF), urea, dicyandiamide, methanol, dichloromethane were purchased from SigmaAldrich Company Ltd. Deionised water used in all the experiments has a resistivity of $18.1 \mathrm{M} \Omega \cdot \mathrm{cm}$

CN Nanosheets. Dicyandiamide $(2 \mathrm{~g})$ in a closed crucible was heated at $500{ }^{\circ} \mathrm{C}$ for $4 \mathrm{~h}$ in static air with a ramp rate of $5^{\circ} \mathrm{C} / \mathrm{min}$. The yellow solid agglomerates were milled into powders using an agate mortar. $0.5 \mathrm{~g}$ of this as-prepared powders were placed on a ceramic plate and heated at $500^{\circ} \mathrm{C}$ for $4 \mathrm{~h}$ in air with a ramp rate of $10^{\circ} \mathrm{C} / \mathrm{min}$. Then, the $\mathrm{CN}$ nanosheets with light yellow colour were finally obtained. This $\mathrm{CN}$ nanosheets sample was named $\mathrm{CN}$.

Carbon-dots via microwave method ( $\mathbf{m} \mathbf{C D})$. The citric acid $(3 \mathrm{~g}, 15.6 \mathrm{mmol})$ and urea $(1 \mathrm{~g}, 16.7 \mathrm{mmol})$ were added into $8 \mathrm{ml}$ deionised water in a beaker and vigorously stirred to form a transparent solution. This beaker containing solution was then moved into the microwave oven and heated for $10 \mathrm{~min}$ under the power mode 
of $600 \mathrm{~W}$. During the reaction, the solution changed from a colourless liquid to a dark brown porous solid, which indicates the $\mathrm{CD}$ was finally produced ${ }^{46}$. The solid product was then put into an oven and dried at $80^{\circ} \mathrm{C}$ for $10 \mathrm{~h}$ to remove the small residual molecules. The suspension of the crude $\mathrm{CD}$ was purified in a centrifuge at $8000 \mathrm{rpm}$ for $1 \mathrm{~h}$ to remove large or agglomerated particles. The final brown aqueous solution was eluted with a mixture of methanol and dichloromethane at ratios of $1: 2$ and $1: 1(\mathrm{v} / \mathrm{v})$ to obtain ${ }^{\mathrm{m}} \mathrm{CD}$. At last, the resulting ${ }^{\mathrm{m}} \mathrm{CD}$ were dried into solid powders.

mCD/CN nanocomposite. Dicyandiamide (2 $\mathrm{g}$ ) and $\mathrm{x}$ mg of ${ }^{\mathrm{m}} \mathrm{CD}$ obtained above $(x=30,50,70$ and 90 , equal to w.t. $1.5,2.5,3.5$, and $4.5 \%$ to dicyandiamide precursor) were added to $10 \mathrm{~mL}$ of DMF and stirred for $1 \mathrm{~h}$; then the liquid was dried at $60^{\circ} \mathrm{C}$ for $10 \mathrm{~h}$ to completely evaporate DMF. The resulting mixture was placed into a crucible with a cover and annealed at $500{ }^{\circ} \mathrm{C}$ in the air for $4 \mathrm{~h}$ with a ramping rate of $5{ }^{\circ} \mathrm{C} / \mathrm{min}$. The brown solid was washed with DI water and dried at $80^{\circ} \mathrm{C}$, then milled into powders with an agate mortar. A concentration of $0.5 \mathrm{~g}$ of powders was placed on a ceramic plate and heated at $500^{\circ} \mathrm{C}$ for $4 \mathrm{~h}$ in air with a ramp rate of $10^{\circ} \mathrm{C} / \mathrm{min}$. Finally, the $\mathrm{m} \mathrm{CD} / \mathrm{CN}$ nanocomposite was obtained. The samples were denoted as ${ }^{\mathrm{m}} \mathrm{CD}(\mathrm{n}) / \mathrm{CN}(n=1.5,2.5,3.5$ and 4.5$)$ by the weight percentage of carbon-dots in the precursor.

Carbon-dots via sonication method ( $\left.{ }^{\mathbf{S} C D}\right)$. Glucose ( $18 \mathrm{~g}$ ) was dissolved in $200 \mathrm{~mL} 0.5 \mathrm{M} \mathrm{NaOH}$ solution before ultrasonication for $2 \mathrm{~h}^{30}$. A dark brown solution was gradually formed, implying the successful production of the $\mathrm{CD}$. The crude solution was neutralised to $\mathrm{pH}=7$ using $0.1 \mathrm{M} \mathrm{HCl}$. The suspension of the crude $\mathrm{CD}$ was washed by deionised water and purified in a centrifuge at $8000 \mathrm{rpm}$ for $1 \mathrm{~h}$ to remove large or agglomerated particles. At last, the resulting ${ }^{\mathrm{s}} \mathrm{CD}$ were dried into solid powders.

sCD/CN nanocomposite. Pure CN (1 g) was dispersed in $200 \mathrm{~mL}$ of $0.5 \mathrm{M} \mathrm{HCl}$ and ultrasonicated for $4 \mathrm{~h}$ at room temperature before repeated wash with deionised water and centrifugation to remove excess $\mathrm{HCl}^{30}$. Lastly, the protonated $\mathrm{CN}$ was dried in an oven overnight at $70^{\circ} \mathrm{C}$ and then ground into powder. Next, $1 \mathrm{~g}$ protonated $\mathrm{CN}$ and an optimal 3\% w.t. of CD sample was dispersed in $100 \mathrm{~mL}$ of deionised water and sonicated for $15 \mathrm{~min}$ and stirred vigorously at room temperature for $30 \mathrm{~min}$. The mixture was then subjected to hydrothermal treatment in a Teflon-sealed autoclave with stirring at $120^{\circ} \mathrm{C}$ for $4 \mathrm{~h}$ to form the ${ }^{\mathrm{s}} \mathrm{CD} / \mathrm{CN}$ nanocomposite.

Characterisations. The morphologies and structures of the samples were characterised by HRTEM using an FEI Titan Themis microscope, operated at $200 \mathrm{kV}$. UV/Vis spectra were carried out on a Shimadzu UV/Vis 2550 spectrophotometer with an integrating sphere device at RT and transformed to the absorption spectra according to the Kubelka-Munk relation. XPS measurements were recorded by using a Thermo Scientific XPS spectrometer. Time-resolved fluorescence emission spectra were carried out at room temperature with a Fluorescence spectrophotometer (Edinburgh Instruments, FLSP-920) monitoring at $470 \mathrm{~nm}$ (excitation wavelength of $330 \mathrm{~nm}$ ). The X-ray diffraction (XRD) patterns were measured by a PANalytical X'pert MPD Pro diffractometer operated at $40 \mathrm{kV}$ and $40 \mathrm{~mA}$ using $\mathrm{Ni}$-filtered $\mathrm{Cu}$-Ka irradiation (Wavelength $1.5406 \AA$ ). ATR-FTIR spectroscopy was performed using a Perkin-Elmer 1605 FTIR spectrometer in the wavenumber range of $500-4000 \mathrm{~cm}-1$ with a resolution of $0.5 \mathrm{~cm}^{-1}$. Raman spectroscopic measurements were performed on a Renishaw InVia Raman Microscope, using a $325 \mathrm{~nm}$ excitation laser and a wavenumber range of $100-2000 \mathrm{~cm}^{-1}$.

Photocatalysis measurement. Before the photocatalytic reduction of $\mathrm{CO}_{2}, 10 \mathrm{mg}$ photocatalyst and $10 \mathrm{~mL}$ water were added into a septum-sealed borosilicate glass reactor with a volume of $140 \mathrm{~mL}$. Then, the reactor was purged with $\mathrm{CO}_{2}$ for the photoreduction experiment. A $300 \mathrm{~W}$ Xe lamp (Newport) was utilised as a light source, and the light output power was measured by a Newport 918-D calibrated photodetector. During the reaction, the products were analysed by GC (Varian GC450 ) with a thermal conductivity detector (TCD, connected to a molecular sieve column) and a flame ionisation detector (FID, connected to a CP-SIL 5CB capillary column) containing a methanizer equipment. Ar gas was used as the GC carrier gas.

For the isotope-trace experiment, the same photocatalytic process was applied except ${ }^{13} \mathrm{CO}_{2}\left({ }^{13} \mathrm{C} 99 \%\right.$, Sigma-Aldrich) was used as the feed gas. The products containing C-isotope were analysed by GC-MS (Shimadzu QP-2010SE) with a molecular sieve $5 \AA$ capillary column (for CO) or a Rxi-624Sil MS capillary column (for methanol). He gas was used as a carrier gas during the measurement.

The $\mathrm{CH}_{3} \mathrm{OH}$ oxidation conditions: $10 \mathrm{ml} \mathrm{H} \mathrm{H}_{2} \mathrm{O}, 0.12 \mu \mathrm{mol} \mathrm{MeOH}, 10 \mathrm{mg}{ }^{\mathrm{m}} \mathrm{CD} /$ $\mathrm{CN}$ photocatalyst, $300 \mathrm{~W}$ Xenon lamp irradiation with $420 \mathrm{~nm}$ long-pass filter in 1 bar Argon atmosphere.

Fabrication of film electrodes and electrochemical measurements. A total of $10 \mathrm{mg}$ photocatalyst and $10 \mu \mathrm{L}$ Nafion solution ( $5 \mathrm{wt} \%)$ were dispersed in a water/ methanol mixture $(1 \mathrm{~mL}, 1: 1 \mathrm{v} / \mathrm{v})$. After sonication treatment for at least $2 \mathrm{~h}$, the mixture formed a homogeneous catalyst colloid. Before the measurements, the catalyst colloid $(200 \mu \mathrm{L})$ was deposited on an FTO conductive glass with an area of $\sim 1 \mathrm{~cm}^{2}$ to form the working electrode. The photocurrent was measured using three electrodes at $1 \mathrm{~V}$ bias voltage, of which $\mathrm{Ag} / \mathrm{AgCl}$ and $\mathrm{Pt}$ net electrodes were used as the reference and counter electrodes, respectively. The electrolyte was $1 \mathrm{M} \mathrm{NaSO}_{4}$ aqueous solution degassed with $\mathrm{Ar}$.

Calculation of internal quantum efficiency. The internal quantum yields for $\mathrm{CD} /$ $\mathrm{CN}$ photocatalyst was measured using the same experimental setup as the photocatalysis measurement, with a bandpass filter $(\lambda=420,500$, or $600 \mathrm{~nm})$. The average intensity of irradiation after the 420,500 , and $600 \mathrm{~nm}$ bandpass filter was 221,347 , and $398 \mu \mathrm{W} / \mathrm{cm}^{2}$, respectively (calculated by five points measured in the beam).

$$
\text { Absorption }_{\mathrm{t}}=100 \% \times \frac{-\Delta T_{\mathrm{t}}}{T_{0}}=100 \% \times \frac{-\left(T_{\mathrm{t}}-T_{0}\right)}{T_{0}}=-100 \% \times\left(10^{-A}-1\right)
$$

The absorbed light density is $110.9,134.5$, and $132.7 \mu \mathrm{W} / \mathrm{cm}^{2}$ (for $\lambda=420,500$, or $600 \mathrm{~nm}$, respectively). For the photocatalytic reaction, $10 \mathrm{mg} \mathrm{CD} / \mathrm{CN}$ photocatalysts were dispersed into $10 \mathrm{ml}$ DI water. The measurement was carried out under a $300 \mathrm{~W}$ Xe lamp with the bandpass filter for $4 \mathrm{~h}$. The amount of CO and $\mathrm{CH}_{3} \mathrm{OH}$ is 0.00083 and $0.235,0.00025$, and $0.114 \mu \mathrm{mol}$, and 0.00010 and $0.074 \mu \mathrm{mol}$ for 420,500 , and $600 \mathrm{~nm}$ bandpass filters, respectively. Also, the irradiation area of the reactor is $\sim 12 \mathrm{~cm}^{2}$. Thus, the IQYs at 420,500 , and $600 \mathrm{~nm}$ is c.a. $2.1,0.7$, and $0.4 \%$, respectively.

The internal quantum yields are defined by the following equation

$$
\mathrm{IQY}=\frac{\text { number of reacted electron }}{\text { number of absorbed photon }} \times 100 \%
$$

Two electrons are consumed per $\mathrm{CO}$ molecule evolved, and six electrons are consumed per $\mathrm{CH}_{3} \mathrm{OH}$ molecule evolved according to reaction (3) or (4).

$$
\begin{gathered}
\mathrm{CO}_{2}+2 \mathrm{e}^{-}+2 \mathrm{H}^{+} \rightarrow \mathrm{CO}+\mathrm{H}_{2} \mathrm{O} \\
\mathrm{CO}_{2}+6 \mathrm{e}^{-}+6 \mathrm{H}^{+} \rightarrow \mathrm{CH}_{3} \mathrm{OH}+\mathrm{H}_{2} \mathrm{O}
\end{gathered}
$$

As a result, the internal quantum efficiency can be estimated by the equation

$$
\mathrm{IQY}=\frac{N_{\mathrm{CO}} \times 2 \times N_{\mathrm{A}}+N_{\mathrm{MeOH}} \times 6 \times N_{\mathrm{A}}}{H_{\mathrm{a}} \times A \times \frac{\lambda}{h c} \times t}
$$

where $N_{\mathrm{CO}}$ is the amount of $\mathrm{CO}$ after $4 \mathrm{~h}$ reaction, $N_{\mathrm{MeOH}}$ is the amount of $\mathrm{CH}_{3} \mathrm{OH}$ after $4 \mathrm{~h}$ reaction, $N_{\mathrm{A}}$ is the Avogadro's number, $H_{\mathrm{a}}$ is the average intensity of absorbed light, obtained by the subtraction of the transmitted intensity from the incident intensity. $A$ is the irradiation area $\left(12 \mathrm{~cm}^{2}\right), h$ is the Planck's constant, $c$ is the speed of light, $\lambda$ is the wavelength of the incident light, $t$ is the time.

\section{Data Availability}

The source data underlying Figs. 1a,d-f, 2a-h, 3a-f and 4a,c and Supplementary Figs $2 \mathrm{a}-\mathrm{d}, 3 \mathrm{a}-\mathrm{c}, 4$ and $5 \mathrm{a}-\mathrm{d}$ are provided as a Source Data file.

Received: 19 November 2019; Accepted: 22 April 2020; Published online: 21 May 2020

\section{References}

1. Hansen, J. E. Scientific reticence and sea level rise. Environ. Res. Lett. 2, 024002 (2007).

2. Seneviratne, S. I., Donat, M. G., Pitman, A. J., Knutti, R. \& Wilby, R. L. Allowable $\mathrm{CO}_{2}$ emissions based on regional and impact-related climate targets. Nature 529, 477 (2016)

3. Forkel, M. et al. Enhanced seasonal $\mathrm{CO}_{2}$ exchange caused by amplified plant productivity in northern ecosystems. Science 351, 696-699 (2016).

4. Blankenship, R. E. et al. Comparing photosynthetic and photovoltaic efficiencies and recognizing the potential for improvement. Science 332 , 805-809 (2011)

5. Inoue, T., Fujishima, A., Konishi, S. \& Honda, K. Photoelectrocatalytic reduction of carbon dioxide in aqueous suspensions of semiconductor powders. Nature. 277, 637 (1979)

6. Tang, J., Durrant, J. R. \& Klug, D. R. Mechanism of photocatalytic water splitting in $\mathrm{TiO}_{2}$. reaction of water with photoholes, importance of charge carrier dynamics, and evidence for four-hole chemistry. J. Am. Chem. Soc. 130, 13885-13891 (2008)

7. Sakimoto, K. K., Wong, A. B. \& Yang, P. Self-photosensitization of nonphotosynthetic bacteria for solar-to-chemical production. Science. 351, 74-77 (2016).

8. Rao, H. L., Schmidt, C., Bonin, J. \& Robert, M. Visible-light-driven methane formation from $\mathrm{CO}_{2}$ with a molecular iron catalyst. Nature. 548, 74-77 (2017). 
9. Wang, Y. et al. Current understanding and challenges of solar-driven hydrogen generation using polymeric photocatalysts. Nat. Energy 4, 746-760 (2019).

10. Huang, C. et al. Carbon-doped $\mathrm{BN}$ nanosheets for metal-free photoredox catalysis. Nat. Comm. 6, 7698 (2015).

11. Shi, L., Wang, T., Zhang, H., Chang, K. \& Ye, J. Electrostatic self-assembly of nanosized carbon nitride nanosheet onto a zirconium metal-organic framework for enhanced photocatalytic $\mathrm{CO}_{2}$ reduction. Adv. Funct. Mater. 25, 5360-5367 (2015).

12. Wei, J. et al. A controllable synthesis of rich nitrogen-doped ordered mesoporous carbon for $\mathrm{CO}_{2}$ capture and supercapacitors. Adv. Funct. Mater. 23, 2322-2328 (2013).

13. Godin, R., Wang, Y., Zwijnenburg, M. A., Tang, J. \& Durrant, J. R. Timeresolved spectroscopic investigation of charge trapping in carbon nitrides photocatalysts for hydrogen generation. J. Am. Chem. Soc. 139, 5216-5224 (2017).

14. Lau, V. W.-H et al. Urea-Modified carbon nitrides: enhancing photocatalytic hydrogen evolution by rational defect engineering. Adv. Energy Mater. 7, 1602251 (2017).

15. Martin, D. J. et al. Highly efficient photocatalytic $\mathrm{H} 2$ evolution from water using visible light and structure-controlled graphitic carbon nitride. Angew. Chem. Int. Ed. 53, 9240-9245 (2014).

16. Kang, Y. et al. An amorphous carbon nitride photocatalyst with greatly extended visible-light-responsive range for photocatalytic hydrogen generation. Adv. Mater. 27, 4572-4577 (2015).

17. Liu, J. et al. Metal-free efficient photocatalyst for stable visible water splitting via a two-electron pathway. Science 347, 970-974 (2015).

18. Chen, J., Shen, S., Guo, P., Wu, P. \& Guo, L. Spatial engineering of photoactive sites on g-C3N4 for efficient solar hydrogen generation. J. Mater. Chem. A 2, 4605-4612 (2014).

19. Li, Q. et al. Facile synthesis of porous carbon nitride spheres with hierarchical three-dimensional mesostructures for CO2 capture. Nano Res. 3, 632-642 (2010).

20. Wang, Y. et al. Bandgap Engineering of Organic Semiconductors for Highly Efficient Photocatalytic Water Splitting. Adv. Energy Mater. 1801084, (2018).

21. Li, H., Zhang, X. \& MacFarlane, D. R. Carbon quantum dots/cu2o heterostructures for solar-light-driven conversion of $\mathrm{CO}_{2}$ to methanol. $A d v$ Energy Mater. 5, 1401077 (2015).

22. Martindale, B. C. M. et al. Enhancing light absorption and charge transfer efficiency in carbon dots through graphitization and core nitrogen doping. Angew. Chem. Int. Ed. 56, 6459-6463 (2017).

23. Iwase, A., Ng, Y. H., Ishiguro, Y., Kudo, A. \& Amal, R. Reduced graphene oxide as a solid-state electron mediator in Z-scheme photocatalytic water splitting under visible light. J. Am. Chem. Soc. 133, 11054-11057 (2011).

24. $\mathrm{Wu}, \mathrm{X}$. et al. Control strategy on two-/four-electron pathway of water splitting by multidoped carbon based catalysts. ACS Catal. 7, 1637-1645 (2017)

25. $\mathrm{Li}, \mathrm{H}$. et al. Water-soluble fluorescent carbon quantum dots and photocatalyst design. Angew. Chem. Int. Ed. 49, 4430-4434 (2010).

26. Gupta, V. et al. Luminscent graphene quantum dots for organic photovoltaic devices. J. Am. Chem. Soc. 133, 9960-9963 (2011).

27. Kwon, W., Lee, G., Do, S., Joo, T. \& Rhee, S.-W. Size-controlled soft-template synthesis of carbon nanodots toward versatile photoactive materials. Small 10, 506-513 (2014).

28. Li, X., Rui, M., Song, J., Shen, Z. \& Zeng, H. Carbon and graphene quantum dots for optoelectronic and energy devices: a review. Adv. Funct. Mater. 25, 4929-4947 (2015).

29. Lim, S. Y., Shen, W. \& Gao, Z. Carbon quantum dots and their applications. Chem. Soc. Rev. 44, 362-381 (2015).

30. Ong, W.-J. et al. Unravelling charge carrier dynamics in protonated g-C3N4 interfaced with carbon nanodots as co-catalysts toward enhanced photocatalytic $\mathrm{CO}_{2}$ reduction: A combined experimental and first-principles DFT study. Nano Res. 10, 1673-1696 (2017).

31. Lin, L. et al. Low-temperature hydrogen production from water and methanol using Pt/a-MoC catalysts. Nature 544, 80 (2017).

32. Ohno, T., Murakami, N., Koyanagi, T. \& Yang, Y. Photocatalytic reduction of $\mathrm{CO}_{2}$ over a hybrid photocatalyst composed of $\mathrm{WO}_{3}$ and graphitic carbon nitride $\left(\mathrm{g}-\mathrm{C}_{3} \mathrm{~N}_{4}\right)$ under visible light. J. CO2 Util. 6, 17-25 (2014).

33. Simon, T. et al. Redox shuttle mechanism enhances photocatalytic $\mathrm{H}_{2}$ generation on Ni-decorated CdS nanorods. Nat. Mater. 13, 1013 (2014).

34. $\mathrm{Li}, \mathrm{Y}$. et al. Pitch-derived amorphous carbon as high performance anode for sodium-ion batteries. Energy Storage Mater. 2, 139-145 (2016).

35. $\mathrm{Hu}, \mathrm{C}$. et al. One-step preparation of nitrogen-doped graphene quantum dots from oxidized debris of graphene oxide. J. Mater. Chem. B 1, 39-42 (2013).

36. Qu, L., Liu, Y., Baek, J.-B. \& Dai, L. Nitrogen-doped graphene as efficient metal-free electrocatalyst for oxygen reduction in fuel cells. ACS Nano. 4, 1321-1326 (2010).

37. Wang, Y. et al. Linker-controlled polymeric photocatalyst for highly efficient hydrogen evolution from water. Energy Environ. Sci. 10, 1643-1651 (2017).
38. Li, M. et al. Graphene with atomic-level in-plane decoration of h-BN domains for efficient photocatalysis. Chem. Mater. 29, 2769-2776 (2017).

39. Choi, C. H., Chung, M. W., Kwon, H. C., Park, S. H. \& Woo, S. I. B, N- and P, $\mathrm{N}$-doped graphene as highly active catalysts for oxygen reduction reactions in acidic media. J. Mater. Chem. A 1, 3694-3699 (2013).

40. Gong, Y. et al. Direct chemical conversion of graphene to boron- and nitrogen- and carbon-containing atomic layers. Nat. Commun. 5, 3193 (2014).

41. Ferrari, A. C., Rodil, S. E. \& Robertson, J. Interpretation of infrared and Raman spectra of amorphous carbon nitrides. Phys. Rev. B 67, 155306 (2003).

42. Larkin, P. J., Makowski, M. P. \& Colthup, N. B. The form of the normal modes of s-triazine: infrared and Raman spectral analysis and ab initio force field calculations. Spectrochim. Acta A 55, 1011-1020 (1999).

43. Yang, X. et al. Superparamagnetic graphene oxide-Fe3O4nanoparticles hybrid for controlled targeted drug carriers. J. Mater. Chem. 19, 2710-2714 (2009).

44. Kresse, G. \& Furthmüller, J. Efficiency of ab-initio total energy calculations for metals and semiconductors using a plane-wave basis set. Comput. Mater. Sci. 6, 15-50 (1996)

45. Putri, L. K., Ong, W.-J., Chang, W. S. \& Chai, S.-P. Heteroatom doped graphene in photocatalysis: a review. Appl. Surf. Sci. 358, 2-14 (2015).

46. Qu, S., Wang, X., Lu, Q., Liu, X. \& Wang, L. A biocompatible fluorescent ink based on water-soluble luminescent carbon nanodots. Angew. Chem. Int. Ed. 51, 12215-12218 (2012)

\section{Acknowledgements}

X.L., K.B.M., J.T. acknowledge EPSRC (EP/S018204/2/1), Leverhulme Trust (Grant No: RPG-2017-122) and Newton Advanced Fellowship grant ((NA170422 and NAF\R1 191163).). X.H., Z.X.G. and S.A.S. acknowledge UCL Grace High-Performance Computing Facility (Grace@UCL) and EPSRC (EP/K021192/1, EP/L018330/1). R.G. thanks the FRQNT for postdoctoral funding and NSERC for operational funding. Y.W., J.C. and C.J., acknowledge CSC Scholarship. R.G., J.F.T. and J.R.D. acknowledge ERC AdG Intersolar grant (291482). J.F.T. acknowledges EPSRC CDT (EP/L015277/1). W.Z. thanks EPSRC for Titan Themis S/TEM microscope (EP/L017008/01). We also thank Dr. Jijia Xie for constructive comments on experimental design.

\section{Author Contributions}

J.T. conceived and supervised the entire project. Y.W and X.L. prepared the materials and carried out the photocatalytic activity tests and nano junctions' characterisations. X.H., S.A.S. and Z.G. carried out the simulation and coordinated the whole version. R.G., J.F.T. and J.R.D. carried out the TAS measurements and analysis. C.J. repeated the nano junction synthesis and carried out the methanol oxidation test. K.B.M. did TEM and FTIR analysis. J.C. and W.Z. performed HRTEM characterisation. Y.W., X.L., X.H, R.G wrote the manuscript. All authors contributed to discussion and revisions.

\section{Competing interests}

The authors declare no competing interests.

\section{Additional information}

Supplementary information is available for this paper at https://doi.org/10.1038/s41467 020-16227-3.

Correspondence and requests for materials should be addressed to R.G., Z.G. or J.T

Peer review information Nature Communications thanks the anonymous reviewer(s) for their contribution to the peer review of this work.

Reprints and permission information is available at http://www.nature.com/reprints

Publisher's note Springer Nature remains neutral with regard to jurisdictional claims in published maps and institutional affiliations.

\section{(i)}

Open Access This article is licensed under a Creative Commons Attribution 4.0 International License, which permits use, sharing, adaptation, distribution and reproduction in any medium or format, as long as you give appropriate credit to the original author(s) and the source, provide a link to the Creative Commons license, and indicate if changes were made. The images or other third party material in this article are included in the article's Creative Commons license, unles indicated otherwise in a credit line to the material. If material is not included in the article's Creative Commons license and your intended use is not permitted by statutory regulation or exceeds the permitted use, you will need to obtain permission directly from the copyright holder. To view a copy of this license, visit http://creativecommons.org/ licenses/by/4.0/

\section{(C) The Author(s) 2020}

